\title{
Pemanfaatan Game Tower Defense Sebagai Media Edukasi Digital
}

\author{
R. Hadapiningrani Kusumohendrarto ${ }^{1}$, Alvanov Zpalanzani $^{2}$ \\ ${ }^{1}$ Sekolah Tinggi Seni Rupa dan Desain Visi Indonesia \\ ${ }^{2}$ Institut Teknologi Bandung \\ E-mail: kusumohendrarto@gmail.com ${ }^{1}$,nova.zp@ gmail.com ${ }^{2}$
}

\begin{tabular}{|c|c|}
\hline ARTICLE INFO & ABSTRACT \\
\hline $\begin{array}{l}\text { Article history: } \\
\text { Received: } 11 \text { Mei } 2018 \\
\text { Revised: } 18 \text { Mei } 2018 \\
\text { Accepted: } 22 \text { Mei } 2018\end{array}$ & $\begin{array}{l}\text { Game is an activity that cannot be separated from human life } \\
\text { because human beings are playing. The growth of digital game on a } \\
\text { smartphone rapidly and widely available in the available online }\end{array}$ \\
\hline $\begin{array}{l}\text { Keywords: } \\
\text { Digital games } \\
\text { Tower defense } \\
\text { Education } \\
\text { Structure analysis }\end{array}$ & $\begin{array}{l}\text { existence of digital games on smartphones is an application shall be } \\
\text { owned by user that is used as a partnership be, a pastime, and as } \\
\text { medium of education. Educational activities are learning activities } \\
\text { and receive information on a person directly or indirectly. The } \\
\text { information provided on recipient's are knowledge or limited a short } \\
\text { message. Tower defense game is one kind of games that can be used } \\
\text { as education to the recipient. With structure analysis method, } \\
\text { elements of education on tower defense games will be analyzed to be } \\
\text { known by both the educational element. }\end{array}$ \\
\hline
\end{tabular}

\section{PENDAHULUAN}

Pertumbuhan permainan digital pada smartphone atau telepon pintar saat ini sangat pesat dan banyak tersedia di available online store atau toko aplikasi penyedia layanan aplikasi dan permainan (game). Permaian digital merupakan sebuah aplikasi yang wajib dimiliki oleh para pengguna smartphone karena fungsinya yang dianggap sebagai sarana hiburan atau pengisi waktu luang.

Permainan atau game merupakan sebuah kegiatan yang tidak dapat lepas dari kehidupan mahluk hidup terutama manusia. Johan Huizinga dalam Wiana menyebutkan bahwa permainan adalah suatu perbuatan atau kegiatan suka rela, yang dilakukan dalam batas-batas ruang dan waktu tertentu yang sudah ditetapkan, menurut aturan yang telah diterima secara suka rela tapi mengikat sepenuhnya, dengan tujuan dalam dirinya sendiri, disertai oleh perasaan tegang dan gembira, dan kesadaran "lain daripada kehidupan sehari-hari". Dimaksudkan oleh Johan 
Huizinga bahwa manusia merupakan mahluk bermain yang dalam sebuah permainan terdapat unsur edukasi atau belajar dalam permainan tersebut (Wiana, 2012).

Edukasi sendiri merupakan kegiatan belajar atau menerima informasi pada seseorang dengan langsung ataupun tidak langsung (secara sadar ataupun tidak sadar) telah menerima informasi dari si pemberi informasi. Informasi tersebut bisa berupa pengetahuan ataupun sebatas pesan singkat.

\section{METODE PENELITIAN}

Pada penelitian ini penulis menggunakan metode penelitian kualitatif deskriptif, dimana pada penelitian ini akan menggunakan contoh kasus permainan dengan jenis atau genre tower defense sebagai bahan penelitian. Data-data dan bahan penelitian dikumpulkan, dikelompokkan, disusun, dan dideskripsikan serta disimpulkan pada bagian akhir. Data-data permainan dan edukasi akan dianalisa sesuai dengan beberapa kesamaan sehingga menghasilkan sebuah analisa teori dari kesamaan tersebut.

\section{PEMBAHASAN}

\subsection{Game Tower Defense, Edukasi, dan Teori Mechanical Game}

\subsubsection{Game tower defense (permainan menara pertahanan)}

Tower defense atau dapat disebut dengan menara pertahanan, adalah subgenre game dari game real-time strategy. Tujuan dari permainan ini adalah untuk mempertahankan markas dan menghentikan musuh yang menyerang ke markas. Membangun unit perangkap, penghalang, pelambat, serta penyerang untuk melakukan perlawanan terhadap musuh yang menyerang atau menghancurkan markas merupakan sebuah perlawanan yang diberikan kepada pemain terhadap game ini. Unit yang dimiliki dan unit musuh memiliki kemampuan yang bervariasi, sehingga dibutuhkan strategi yang tepat dalam bermain dan tidak sembarangan dalam memilih unit untuk melakukan perlawanan terhadap musuh. Kemampuan yang bervariasi oleh unit terkadang membutuhkan item yang berbeda dan harga yang berbeda untuk dapat membeli unit pertahanan. Ketika musuh dikalahkan, biasanya pemain mendapatkan uang atau poin ataupun item, yang digunakan untuk membeli atau meng-upgrade menara, atau upgrade jumlah uang atau poin yang diperoleh, atau bahkan meng-upgrade tingkat dimana mereka meng-upgrade.

Untuk membuat sebuah game tower defense sendiri dibutuhkan beberapa elemen pendukung dalam game tersebut, seperti: 
- Person (pemain): Person atau orang atau pemain, fungsi dari pemain disini adalah sebagai pihak yang akan mengatur strategi pertahanan markas dengan meletakkan unitunit pelindung markas. Sehingga tanpa adanya pemain yang menjalankan game tower defense maka tidak dapat disebut sebagai game atau game tower defense.

- Strategi: Merupakan cara berpikir untuk dapat bertahan atau tindakan yang tidak dilakukan secara gegabah. Dalam bermain game tower defense ini pun pemain memerlukannya strategi yang berbeda di setiap levelnya. Oleh sebab itu game tower defense disebut sebagai subgenre dari game real-time strategy.

- Unit Pelindung: Unit pelindung adalah unit pada game tower defense yang bertugas untuk melindungi markas dari serangan musuh sehingga musuh tidak dapat menghancurkan markas yang harus tetap terjaga hingga permainan berakhir. Unit pelindung sendiri terbagi menjadi 3 yakni unit penyerang, unit penghalang, dan unit perangkat.

- Unit Musuh: Adalah pelawan yang akan menyerang markas. Unit musuh biasanya terbagi oleh 2 kategori yakni unit penyerang biasa (anak buah) dan unit penyerang hebat (ketua atau bos). Penyeranganpun dilakukan tidak secara langsung oleh unit bos untuk menyerang, melainkan penyerangan akan dilakukan oleh unit anak buah terlebih dahulu dan kemudian diikuti oleh unit bos dalam penyerangan selanjutnya.

- Arena: Merupakan sebuah tempat terjadinya pertempuran berlangsung antara unit pelindung markas dengan unit musuh penyerang markas.

- Waktu: Dalam sebuah pertempuran dibutuhkannya waktu untuk mengetahui sebuah penyerangan sedang ataupun akan berlangsung, sehingga pemain akan bersiap-siap untuk melakukan pertahanan dan mengetahui kapan pertempuran akan selesai atau berhenti.

- Cerita: Dibutuhkannya sebuah jalan cerita untuk melatar belakangi adanya sebuah permainan menara pertahanan, sehingga pemain akan mengetahui permainan menara pertahanan dengan cerita apa yang sedang dimainkannya. 


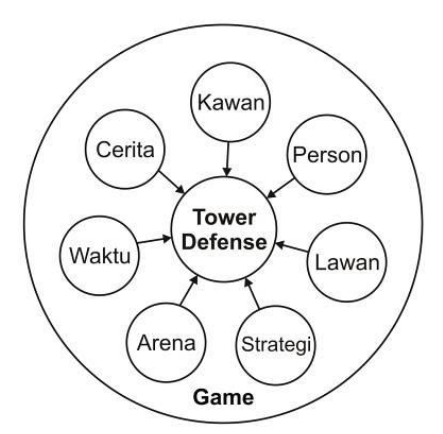

Bagan 1. Unsur-unsur game tower defense - Akumulasi dari unsur game tower defense

- "Elf Defense": Merupakan game digital buatan Korea yang saat ini cukup diminati oleh para pemain game digital khususnya subgenre real time strategy yakni tower defense. Merupakan game yang menarik dengan tampilan visual yang menyenangkan dan mudah diterima atau dimengerti.

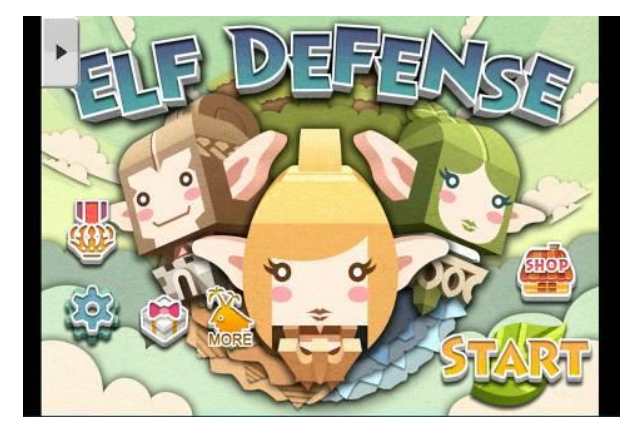

Gambar 1. Menu utama pada game tower defense "Elf Defense".

(Sumber: Dokumentasi penulis, 23 Oktober 2013)

- "Kingdom Rush": Perkembangan game dengan subgenre real time strategy (RTS) cukup memiliki pangsa pasar game, dengan diberikannya cerita dan visual yang menarik, pemain akan tertarik dan mencobanya. "Kingdom Rush" merupakan game tower defense dengan sebuah tema kerajaan jaman dahulu kala. "Kingdom Rush” merupakan salah satu game tower defense yang membutuhkan konektivitas internet sebagai akses untuk bermain, "Kingdom Rush" dapat dimainkan pada sebuah situs game online "Armorgames". 


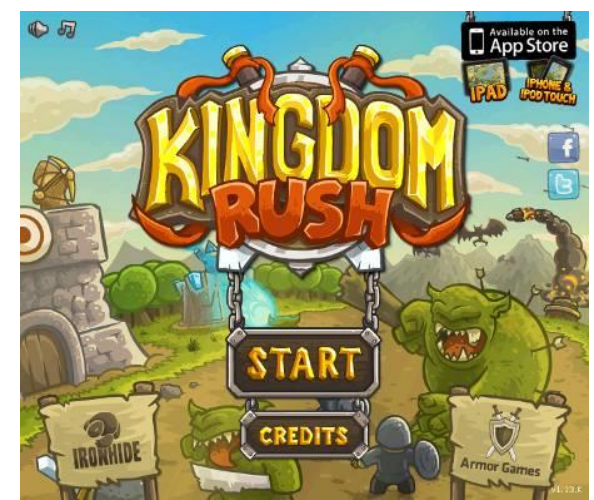

Gambar 2. Main Menu pada game tower defense "Kingdom Rush".

(Sumber : Dokumentasi penulis, 23 Oktober 2013)

\subsubsection{Edukasi atau pendidikan}

Pendidikan adalah bagian dari perjalan hidup manusia. Pendidikan dalam bahasa Inggris berasal dari kata "educate" yang artinya mendidik, memberi peningkatan, dan mengembangkan. Pendidikan adalah sebuah rangkaian proses yang tiada henti demi pengembangan kemampuan serta perilaku yang dimiliki oleh individu agar dapat dimanfaatkan bagi kehidupannya. Banyak orang yang memahami pendidikan sebagai sebuah pengajaran. Pendidikan sendiri merupakan usaha sadar dan terencana untuk pembelajaran agar peserta didik secara aktif mengembangkan potensi dirinya untuk memiliki kekuatan spiritual keagamaan, pengendalian diri, kepribadian, kecerdasan, akhlak mulia, serta keterampilan yang diperlukan dirinya dan masyarakat.

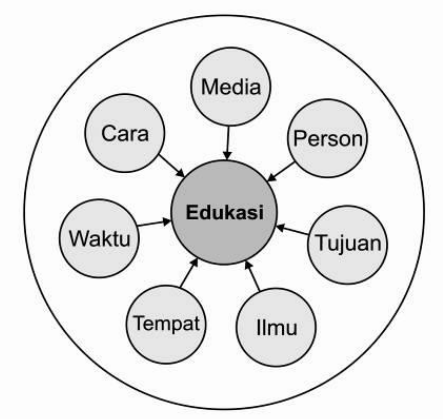

Bagan 2. Game (bermain) adalah edukasi - Akumulasi dari teori Johan Huizinga "manusia mahluk bermain".

Berdasarkan akumulasi dari teori Edukasi Johan Huizinga "manusia mahluk bermain" maka elemen-elemen edukasi tersebut dapat dijelaskan sebagai berikut:

- Media: Perantara ataupun sebuah penghubung yang digunakan untuk menghubungkan sesuatu dengan sesuatu. Sebuah permainan merupakan sebuah media (penghubung) antara manusia dengan ilmu pengetahuan yang terdapat dalam permainan tersebut. 
- Person atau Orang atau Penerima: Manusia merupakan objek yang menerima sesuatu dari si pemberi (permainan). Sehingga manusia akan mendapatkan ilmu pengetahuan dari sebuah permainan yang dimainkannya.

- Tujuan: Arah, haluan (jurusan) ataupun maksud. Manusia sebagai mahluk bermain secara tidak langsung memiliki tujuan yakni hanya bermain sebuah permainan. Namun tidak menyadari bahwa permainan yang dimainkannya tersebut akan mendapatkan sebuah ilmu pengetahuan baru nantinya.

- Ilmu: Pengetahuan tentang suatu bidang yang disusun secara sistematis menurut metodemetode tertentu yang dapat dipergunakan untuk menerangkan gejala-gejala tertentu dalam bidang pengetahuan tersebut. Ilmu pengetahuan merupakan hal tersembunyi yang terdapat dalam sebuah permainan. Sehingga manusia tidak tahu akan belajar atau mendapatkan apa dari sebuah permainan yang dimainkannya nanti.

- Tempat: Sesuatu yang dipakai untuk menaruh ataupun menyimpan, ruang untuk melakukan sesuatu. Karena manusia merupakan mahluk bermain, maka setiap tempat yang disinggahinya atau dimainkannya akan mendapatkan ilmu pengetahuan baru. Namun sedikit yang menyadari bahwa sebenarnya manusia sedang mendapatkan ilmu pengetahuan di mana pun ia berada.

- Waktu: Seluruh rangkaian saat ketika proses, perbuatan atau keadaan berada atau berlangsung. Waktu terus dan selalu berputar, dalam sebuah permainan akan dipertanyakan selama apa manusia akan bermain? Maka ilmu apa dan seberapa banyak ilmu yang akan didapatnya dalam permainan tersebut.

- Cara: Menurut Kamus Besar Bahasa Indonesia, "cara" adalah jalan (aturan, sistem) melakukan (berbuat dsb) sesuatu. "Cara" adalah suatu jalan (aturan, sistem) disertai tindakan untuk melakukan ataupun berbuat sesuatu. Sehingga dalam melakukan sebuah permainan manusia pun akan mempunyai caranya masing-masing untuk bermain dan mendapatkan ilmu dari permainannya tersebut.

\subsubsection{Teori mechanical game}

Jesse Schell (2008) menjelaskan bahwa mechanical game adalah inti dari sebuah game atau yang menjadi dasar dari sebuah game, yakni berupa interaksi dan memiliki hubungan yang tetap ketika unsur estetika, teknologi, dan cerita dihilangkan. Game design secara umum tidak memiliki taksonomi game mekanik yang disepakati, karena memiliki mekanisme gameplay yang sederhana, cenderung kompleks, dan sulit diurai. Salah satu cara yaitu dengan menyederhanakan mekanisme kompleks ke titik matematis sempurna dengan hasil pemahaman sistem deskripsi 
yang tidak lengkap. Sehingga jarang dipakai untuk merancang game nyata. Pada satu kenyataan, game mekanik sangat objektif sejelas membuat aturan. Namun di sisi lain game mekanik mempunyai sesuatu hal yang cukup misterius dalam sebuah permainan. Beberapa elemen dari game mekanik yang dapat diklasifikasikan untuk memberikan wawasan serta pengetahuan kepada game design antara lain: (1) Ruang (space); (2) Objek, Atribut, dan Kesatuan; (3) Tindakan; (4) Aturan; (5) Kemampuan; dan (6) Kesempatan.

\subsection{Analisis}

\subsubsection{Analisis game mekanik dalam game tower defense}

Dalam pembuatan game tower defense sendiri dibutuhkannya elemen dasar dari sebuah unsur pendukung utama game yakni adanya elemen game mekanik dalam genre game tersebut. Sehingga dalam pembuatan game tower defense elemen game mekanik akan dipadukan dengan elemen game tower defense yang kemudian menghasilkan sebuah game utuh bergenre tower defense.

\subsubsection{Analisis formulasi teori edukasi dan teori game tower defense pada game}

Dari game towe defense "Kingdom Rush" dan "Elf Defense" dapat dilihat adanya hubungan antara teori edukasi pada game tower defense. Hubungan keterkaitan antara teori edukasi dan game tower defense akan dijelaskan sebagai berikut:

- Person atau pemain atau penerima pesan: Adanya interaksi yang harus dilakukan oleh pemain terhadap game yang dimainkannya merupakan kegiatan dari sebuah permainan atau kegiatan edukasi untuk menerima pesan dari permainan tersebut. Person atau pemain atau orang disini berperan sebagai pengatur jalannya permainan, namun lebih sebagai pengatur strategi pertahanan markas. Pemain harus dapat mengatur unit-unit menara pertahanan ketika permainan dimulai. Pemain disini juga berfungsi sebagai obyek penerima pesan dalam game atau sebagai elemen penting kegiatan edukasi dalam game. Sebuah pembelajaran atau edukasi tidak dapat tersampaikan jika tidak adanya penerima, untuk game sendiri tidak dapat dikatakan sebuah permainan jika di dalamnya tidak terdapat pemain yang akan memainkan permainan tersebut. 


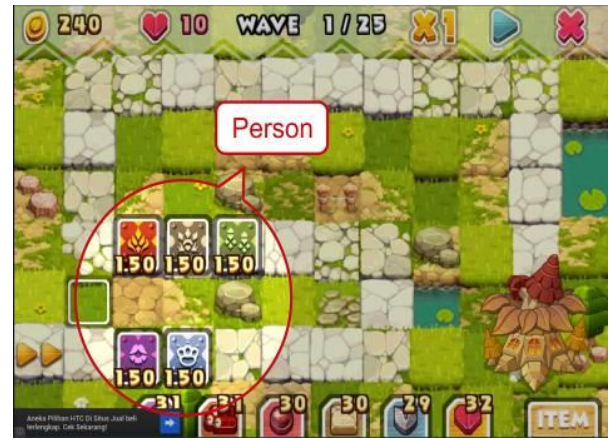

Gambar 3. "Elf Defense" - Person. (Sumber: Jellyoasis.inc, 2011)

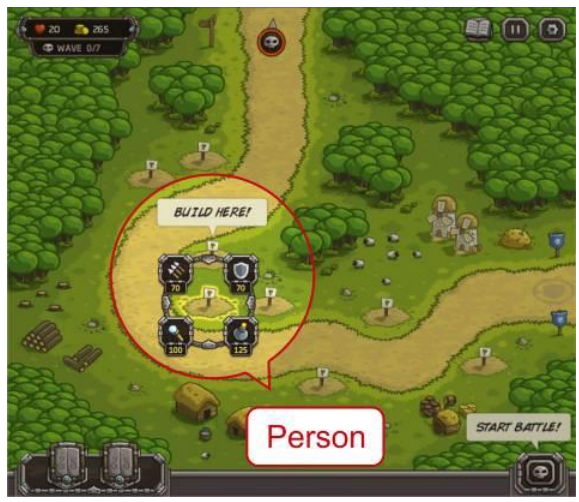

Gambar 4. "Kingdom Rush" - Person. (Sumber: IronHide Game Studio, 2011)

- Arena: Arena dalam game tower defense merupakan tempat terjadinya perlawanan antara unit pelindung dengan unit musuh berlangsung. Dengan maksud sebuah tempat dimana adanya kegiatan berlangsung dan terjadi, baik itu kegiatan bermain sebuah permainan ataupun kegiatan edukasi yang membutuhkan tempat sebagai penyampai pesan. Arena atau tempat sendiri merupakan elemen penting dari teori edukasi dan teori game tower defense sehingga elemen arena tidak dapat dilepaskan begitu saja dari teori-teori tersebut.

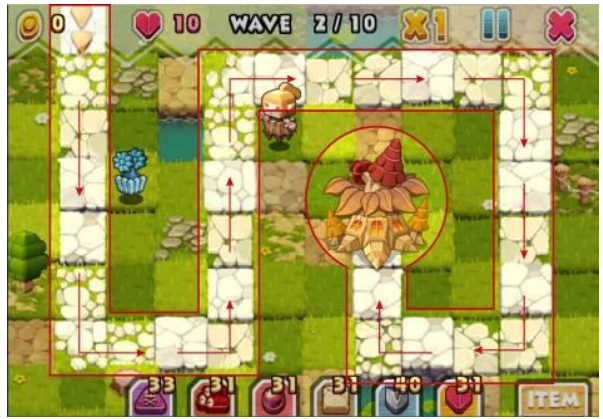

Gambar 5. "Elf Defense" - Arena.

(Sumber: Jellyoasis.inc, 2011) 


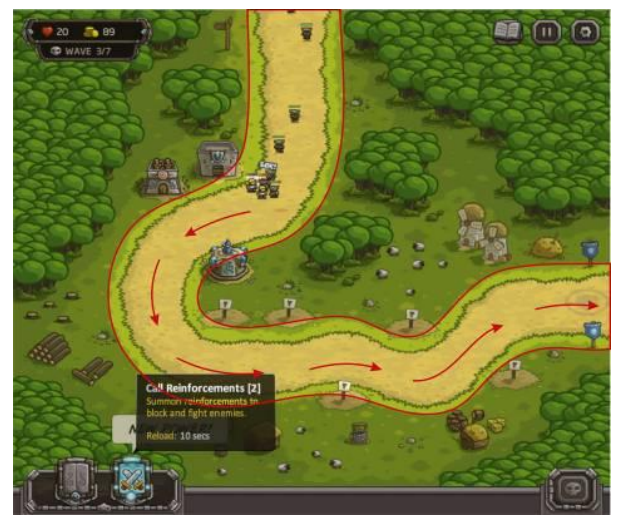

Gambar 6. "Kingdom Rush" - Arena.

(Sumber: IronHide Game Studio, 2011)

Pada permainan "Elf Defense" dan "Kingdom Rush", pemain diberikan sebuah arena atau tempat yang berbeda karena perbedaan permainan dan perbedaan pesan yang ingin disampaikan permainan tersebut. Dengan hal seperti ini maka pemain akan belajar mengetahui atau menebak tempat atau keberadaan permainan tersebut. Seperti pada permainan "Kingdom Rush" memberikan unsur edukasi tempat lewat sebuah cerita jaman dahulu yang masih terdapatnya hutan lebat, kemudian manusia membuat sebuah peradaban pada hutan tersebut dengan membangun sebuah desa yang kemudian dipimpin oleh sebuah kerajaan. Kemudian pemain dapat belajar mengetahui tempat baru yang ia kunjungi atau berada dan pada tahun berapa permainan tersebut ber-settingkan. Berbeda halnya dengan "Elf Defense", "Elf Defense" menyajikan tempat kehidupan dunia ras peri yakni berupa hutan suci yang harus dijaga oleh para peri melalui seorang pemain yang akan mengatur strategi bertahan pada arena tersebut, sehingga penyerangan oleh ras manusia dapat dihentikan. Untuk "Elf Defense", pemain akan mengetahui dan menebak ia sedang berada dimana sekarang (saat bermain) dan ia akan belajar di tempat mana iklim tersebut mempengaruhi tempat ia berada. Kemudian dapat terlihat dari segi arena yang digunakan yakni sangat berbeda seperti, Kingdom Rush memiliki arena yang acak dan berbeda-beda di setiap levelnya dan memiliki tempat memasang menara pertahanan yang terbatas. "Elf Defense" memiliki arena yang hampir sama seperti "Kingdom Rush" (arena yang acak di setiap level), namun "Elf Defense" dapat memasang menara pertahanan di setiap pinggir lintasan serangan.

- Strategi atau cara: Cara atau strategi merupakan unsur edukasi dan unsur game tower defense yang secara tidak sadar seseorang sedang mempelajarinya. Edukasi memerlukan sebuah unsur cara untuk tersampaikannya pesan yang ada di dalamnya. Dalam game 
tower defense sendiri sebuah strategi dipelajari secara bertahap hingga terselesaikannya permainan yang dimainkan seorang pemain, dan strategi dalam game tower defense tersebut secara tidak langsung dipelajarinya saat bermain.

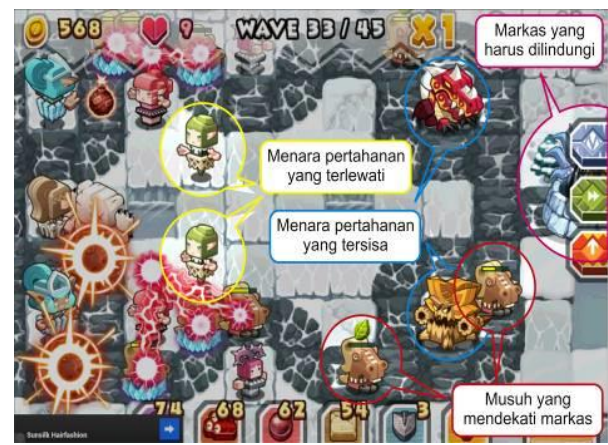

Gambar 7. "Elf Defense" - Strategi.

(Sumber: Jellyoasis.inc, 2011)

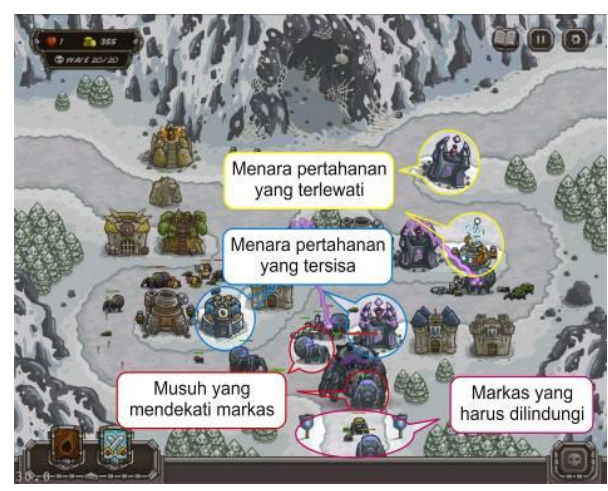

Gambar 8. "Kingdom Rush"- Strategi.

(Sumber: IronHide Game Studio, 2011)

Cara atau strategi merupakan unsur edukasi dan unsur game tower defense yang secara tidak sadar seseorang sedang mempelajarinya. Edukasi memerlukan sebuah unsur cara untuk tersampaikannya pesan yang ada di dalamnya. Dalam game tower defense sendiri sebuah strategi dipelajari secara bertahap hingga terselesaikannya permainan yang dimainkan seorang pemain, dan strategi dalam game tower defense tersebut secara tidak langsung dipelajarinya saat bermain.

- Wave (gelombang) atau Waktu: Kemudian unsur kesamaan yang terdapat antara teori edukasi dan game tower defense yaitu terdapat pada unsur waktu, seperti yang kita ketahui bahwa sebuah kegiatan edukasi atau sebuah pembelajaran membutuhkan unsur waktu dan sering tidak kita ketahui jika sebenarnya hampir setiap saat kita selalu belajar atau beredukasi terhadap apapun yang sedang kita hadapi atau temui. Permainan membutuhkan unsur waktu untuk dapat memberikan unsur pembelajaran terhadap apa 
yang dimainkan pemain pada sebuah permainan. Pada game tower defense unsur waktu terdapat pada waktu penyerangan atau wave dan level yang dimainkan oleh pemain.

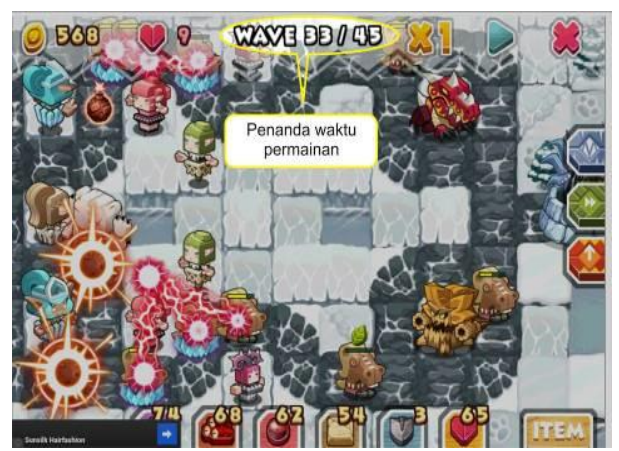

Gambar 9. "Elf Defense" - Wave.

(Sumber: Jellyoasis.inc, 2011)

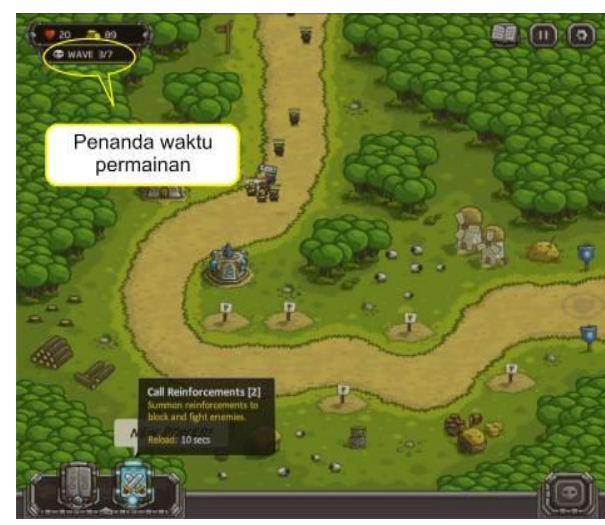

Gambar 10. "Kingdom Rush" - Wave.

(Sumber: IronHide Game Studio, 2011)

Pada "Elf Defense" unsur waktu terlihat yakni pada waktu penyerangan atau "wave" atau disebut dengan gelombang penyerangan, yang dimana pemain akan mengetahui dan beredukasi tentang waktu saat semakin sempitnya waktu penyerangan manusia terhadap para peri maka penyerangan yang dilakukan pun akan semakin cepat dan kuat, begitupula pada Kingdom Rush. Namun pada Kingdom Rush unsur waktu lain dapat terlihat pada setting tempat dan abad pertengahan yang dapat terlihat dari pakaian yang digunakan oleh para prajurit kerajaan dan cerita mitologi yang berupa terdapatnya sosok monster.

- Intro atau Cerita: Unsur tujuan dari edukasi dan unsur cerita dari pada tower defense memiliki unsur tujuan atau cerita yang akan diberikan kepada pemain dengan maksud pemain akan mengetahui jalan cerita dari permainan yang dimainkannya. Sehingga pemain dapat diedukasi dengan memahami atau mengerti jalan cerita dari permainan yang dimainkannya. Dari intro pada game tower defense, pemain akan sedikit 
mengetahui sedikit jalan cerita dari permainan yang akan dimainkannya nanti. Sehingga pemain akan mengerti akan melakukan tindakan apa pada permainannya nanti.

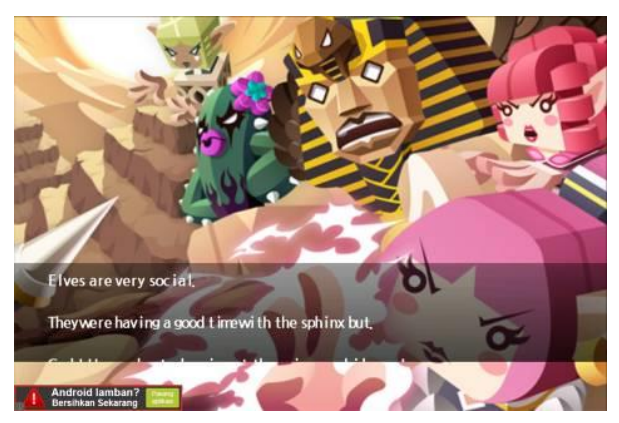

Gambar 11. "Elf Defense" - Intro.

(Sumber: Jellyoasis.inc, 2011)

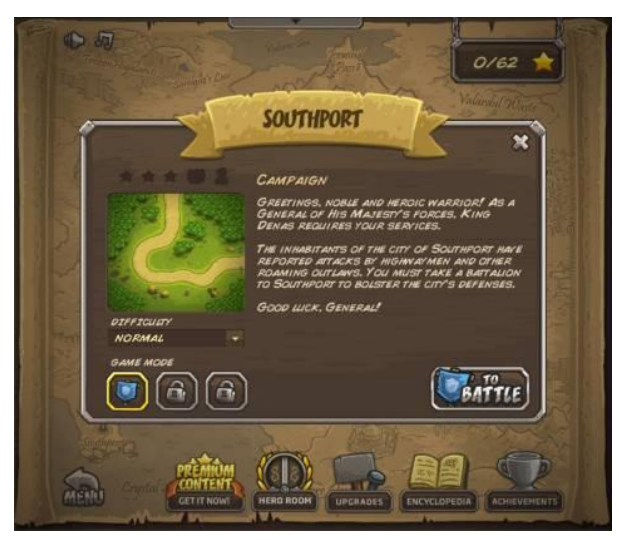

Gambar 12. Kingdom Rush - Intro [4] (Sumber: IronHide Game Studio, 2011)

Unsur cerita pada "Kingdom Rush" berupa pertahanan pasukan kerajaan yang berusaha menghalangi penyerangan para monster untuk dapat sampai di kerajaan, dan "Elf Defense" sendiri merupakan pertahanan sekelompok tanaman dan hewan suci di dunia ras peri terhadap ketamakan manusia yang akan ingin mengeksploitasi dunia ras peri.

\subsection{Hasil analisis teori edukasi dan teori game tower defense}

Melihat beberapa kesamaan yang terdapat pada teori edukasi dan game tower defense maka dapat diakumulasikan beberapa kesamaan atau relevansi yang dapat diformulasikan menjadi seperti berikut : 


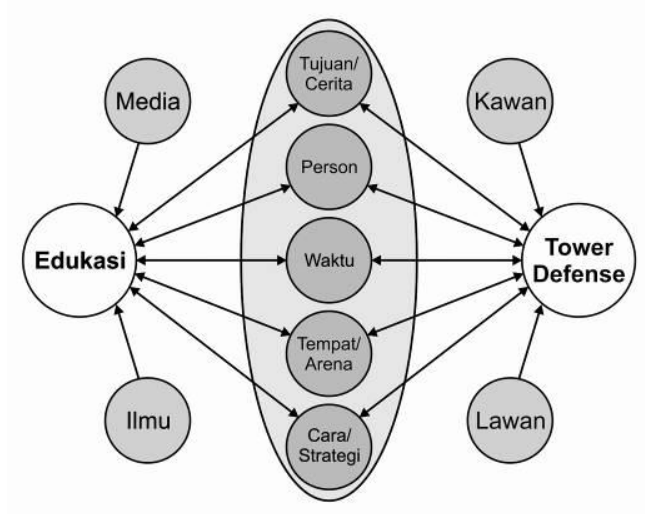

Bagan 3. Formulasi teori edukasi - game tower defense.

Adanya kesamaan elemen-elemen antara teori edukasi dengan teori game tower defense maka elemen-elemen tersebut merupakan elemen penting dalam sebuah game tower defense untuk dapat menyampaikan pesan edukasi kepada pemain. Adanya pesan atau edukasi di dalam game tower defense merupakan tujuan dari pembuat game kepada pemain game.

Sehingga unsur media pada edukasi dapat menggunakan perantara sebuah game tower defense yang dapat dimasukkan ilmu-ilmu pengetahuan atau edukasi ke dalamnya. Untuk unsur kawan dan lawan pada game tower defense dapat dijadikan sebagai bahan ilmu edukasi dalam kegiatan edukasi pada saat pemain sedang bermain.

\section{KESIMPULAN}

Game tower defense merupakan subgenre dari game real time strategy. Kekhasan game tower defense dapat diketahui melalui cara bermain dan unsur cerita yang dibangun oleh pembuat game. Dari contoh 2 game tower defense diatas dapat dilihat adanya perbedaan cerita serta perbedaan elemen edukasi yang disajikan oleh pembuat game terhadap pemain. Namun dari segi edukasi game tower defense mengajarkan edukasi bermain strategi layaknya permainan catur.

Beberapa game tower defense di atas merupakan game tower defense yang memiliki cara bermain yang hampir sama dan memiliki perbedaan pada unsur cerita yang disajikan, sehingga game tower defense menyajikan kepada pemain berupa bagaimana cara menyusun strategi bertahan dengan menggunakan menara pertahanan untuk menghalangi atau menghentikan penyerangan musuh sebelum sampai di markas. Tidak semua game tower defense mengandung unsur atau relevansi edukasi di dalamnya karena setiap game tower defense memiliki keanekaragaman dan ketidak samaan antara satu dengan yang lain. 


\section{DAFTAR PUSTAKA}

Schell, Jesse., 2008. The Art of Game Design a Book of Lenses. USA: Morgan Kaufmann Publishers.

Wiana, R.D., 2012. Perancangan Game Galah Asin Untuk Memperkenalkan Budaya Tradisional Jawa Barat. Wimba, Jurnal Komunikasi Visual \& Multimedia, Vol. 04 No. 2. Hal: 73-86.

Jellyoasis inc: Elf Defense, Program and Team Manager: Jong Hwa and Bae, Graphic Artist: In Jae and Byun, Game Planner: Dan and Kim, South Korea. http://jellyoasis.net. Diakses pada 2011.

IronHide Game Studio: Kingdom Rush, Development Team: Alvaro Azofra, Pablo Realini, and Gonzalo Sande, Music: Taking Off Studio, Voice Talent: Sean Crisden Studio, Map Music: Hyperduck SoundWorks Studio, Narrative: Martin A Perez. http://www.ironhidegames.com. Diakses pada 2011.

http://armorgames.com/. Diakses pada 2011. 